\title{
MODELLING ANIMAL SYSTEMS PAPER Sensitivity analysis of an early egg production predictive model in broiler breeders based on dietary nutrient intake
}

\author{
A. FARIDI ${ }^{1 *}$, M. MOTTAGHITALAB ${ }^{2}$ AND H. AHMADI ${ }^{3}$ \\ ${ }^{1}$ Department of Animal Science, Islamic Azad University, Sanandaj Branch, Kordestan, Iran \\ ${ }^{2}$ Department of Animal Science, Faculty of Agricultural Sciences, University of Guilan, PO Box 41635-1314, Rasht, Iran \\ ${ }^{3}$ Center of Excellence in the Animal Science Department, Ferdowsi University of Mashhad, 91775-1163, Mashhad, Iran
}

(Received 29 May 2010; revised 9 February 2011; accepted 21 March 2011; first published online 3 June 2011)

\section{SUMMARY}

Neural networks (NNs), especially the group method of data handling-type NN (GMDH-type NN), are new tools in modelling growth and production in poultry systems. In the present study, the GMDH-type NN was used to model early egg production (EEP, eggs/bird) in Ross 308 broiler breeders (BBs) from 24 to 29 weeks of age based on their dietary energy and nutrient intake. The selected input variables were intake levels of metabolizable energy (ME; MJ/bird/day), crude protein (CP; g/bird/day), methionine (Met; g/bird/day), and lysine (Lys; g/bird/day). A sensitivity analysis (SA) technique was utilized to evaluate the relative importance of input variables on model output. The GMDH-type NN revealed a high ability in the modelling of EEP based on the input variables investigated. The SA results indicated that the models developed showed most sensitivity to dietary intake of Met, followed by dietary intake of Lys, ME and CP, respectively. The maximum sensitivity of each input variable was considered as the optimum value for maximizing EEP in BB. The suggested optimum values for dietary nutrient intake were as follows: $1 \cdot 9-2 \cdot 1 \mathrm{MJ} / \mathrm{bird} /$ day for $\mathrm{ME}, 23 \mathrm{~g} / \mathrm{bird} /$ day for $\mathrm{CP}, 0 \cdot 65-0 \cdot 8 \mathrm{~g} / \mathrm{bird} /$ day for Met and $1 \cdot 4-1 \cdot 5 \mathrm{~g} / \mathrm{bird} /$ day for Lys.

\section{INTRODUCTION}

The nutritional requirements of broiler breeders (BBs) and the effect of dietary energy and nutrients on their performance have been reported previously (Latour et al. 1996; Peebles et al. 2000a,b). It has been demonstrated that the levels of dietary metabolizable energy (ME), crude protein (CP), amino acids and level of feed intake play an important role in BB performance in both maintenance and egg production (Wilson \& Harms 1986; Harms \& Ivey 1992; Harms \& Russell 1998). Investigating nutritional strategies to assess the production of poultry is a long-term task, expensive to conduct. Neural network (NN)-based methods are a relatively new option to model growth and production in animal systems. The $\mathrm{NN}$ model is a biologically inspired computing scheme that can uncover highly complex relationships between several input and output variables. A detailed description of $\mathrm{NN}$

* To whom all correspondence should be addressed. Email: ako_faridi@yahoo.com terminology, development and application has been reported by several researchers (e.g. Cheng \& Titterington 1994; Basheer \& Hajmeer 2000). One sub-model of $\mathrm{NN}$ is the group method of data handling-type $\mathrm{NN}$ (GMDH-type $\mathrm{NN}$ ) with an evolutionary method of genetic algorithm (GA; NarimanZadeh et al. 2003). This approach has been applied successfully in several fields of poultry science (Ahmadi et al. 2008; Mottaghitalab et al. 2010; Faridi et al. 2011). The final form of this model is represented as polynomial equations (Farrow 1984). Conducting a sensitivity analysis (SA) on the obtained polynomial equations reveals the sensitivity of model output to input variables. In other words, SA increases confidence in the model and its predictions by providing an understanding of how the model responds to changes in its inputs. Moreover, the SA identifies critical regions in the space of the inputs, establishes priorities for research and simplifies the model (Castillo et al. 2008; Saltelli et al. 2008). Although the use of NN and SA techniques has led to successful application in a broad 
Table 1. Composition and calculated contents of some of the commercial diets fed during the production period $(\mathrm{g} / \mathrm{kg})$

\begin{tabular}{|c|c|c|c|c|c|c|}
\hline \multirow[b]{2}{*}{ Item } & \multicolumn{6}{|c|}{ Diet } \\
\hline & 1 & 2 & 3 & 4 & 5 & 6 \\
\hline Maize & 496 & 503 & 508 & 511 & 485 & 490 \\
\hline Wheat & 200 & 200 & 200 & 200 & 250 & 250 \\
\hline Soybean meal (440 g CP/kg) & $184 \cdot 4$ & $182 \cdot 1$ & $155 \cdot 7$ & $160 \cdot 4$ & $129 \cdot 8$ & $133 \cdot 5$ \\
\hline Oyster shell & $62 \cdot 3$ & 71 & $61 \cdot 3$ & $69 \cdot 2$ & 66 & $65 \cdot 8$ \\
\hline Wheat bran & $20 \cdot 4$ & $7 \cdot 7$ & 38 & $22 \cdot 7$ & $43 \cdot 9$ & $31 \cdot 2$ \\
\hline Dicalcium phosphate & 17 & $17 \cdot 1$ & $16 \cdot 1$ & $16 \cdot 2$ & $16 \cdot 6$ & $16 \cdot 6$ \\
\hline Zeolite & 10 & 10 & 10 & 10 & - & \\
\hline Mineral premix & $2 \cdot 5$ & $2 \cdot 5$ & $2 \cdot 5$ & $2 \cdot 5$ & $2 \cdot 5$ & $2 \cdot 5$ \\
\hline Vitamin premix & $2 \cdot 5$ & $2 \cdot 5$ & $2 \cdot 5$ & $2 \cdot 5$ & $2 \cdot 5$ & $2 \cdot 5$ \\
\hline Common salt & $2 \cdot 3$ & $2 \cdot 3$ & $1 \cdot 9$ & $1 \cdot 9$ & $2 \cdot 2$ & $2 \cdot 7$ \\
\hline Sodium bicarbonate & $1 \cdot 5$ & $1 \cdot 5$ & 2 & 2 & - & $2 \cdot 4$ \\
\hline DL-Met & $0 \cdot 8$ & $0 \cdot 8$ & $0 \cdot 8$ & $0 \cdot 9$ & - & $1 \cdot 1$ \\
\hline L-Lys HCL & - & - & 1 & 1 & $0 \cdot 5$ & $0 \cdot 5$ \\
\hline \multicolumn{7}{|l|}{ Content by calculation } \\
\hline ME (MJ/kg) & $11 \cdot 51$ & $11 \cdot 51$ & $11 \cdot 51$ & $11 \cdot 51$ & $11 \cdot 72$ & $11 \cdot 72$ \\
\hline Protein & $148 \cdot 7$ & $146 \cdot 3$ & $147 \cdot 9$ & $147 \cdot 9$ & $145 \cdot 0$ & $145 \cdot 0$ \\
\hline Met & $3 \cdot 2$ & $3 \cdot 2$ & $3 \cdot 2$ & $3 \cdot 3$ & $3 \cdot 4$ & $3 \cdot 5$ \\
\hline Lys & $7 \cdot 0$ & $6 \cdot 9$ & $7 \cdot 5$ & $7 \cdot 5$ & $6 \cdot 5$ & $6 \cdot 5$ \\
\hline Calcium & 28 & 31 & 28 & 318 & 30 & 30 \\
\hline Available $P$ & $3 \cdot 5$ & $3 \cdot 5$ & $3 \cdot 5$ & $3 \cdot 5$ & $3 \cdot 5$ & $3 \cdot 5$ \\
\hline
\end{tabular}

range of areas (Kucuk \& Derebasi 2006; Seyedan \& Ching 2006; Lee \& Hsiung 2009), the use of SA along with NN models is uncommon in poultry science. The aim of the present study was to use the GMDH-type $\mathrm{NN}$ to model early egg production (EEP) in BB based on the dietary intake levels of $\mathrm{ME}, \mathrm{CP}$, and the two first limiting amino acids, methionine (Met) and lysine (Lys). The SA method was utilized to evaluate the relative importance of input variables on model output and to determine the optimum levels of nutrient intake for obtaining the maximum EEP in BB.

\section{MATERIALS AND METHODS}

\section{Data source}

Data used in the current study were obtained from two local commercial BB farms (at Mazandaran, Iran, $36^{\circ} 28^{\prime} \mathrm{E}, 5^{\circ}{ }^{\circ} 7^{\prime}$ ) (Ross 308) during EEP (24-29 weeks). Data were collected from three flocks, with 12 saloons (rooms within a poultry barn) each, where each saloon provided a data line. The average number of birds in each saloon was 3500 , with initial weight of $3.05 \mathrm{~kg}$ at 24 weeks of age. In that period, the flocks produced 67 data lines. Each data line consisted of average dietary intake levels of ME (MJ/bird/day), CP (g/bird/day), Met (g/bird/day) and Lys (g/bird/day) and weekly egg production (eggs/bird) during 24-29 weeks of age. All flocks were in the first cycle of production and fed with maize-soybean meal diets. The feeding programmes were based on the Ross parent stock company (Ross Breeders Ltd 2005). The composition and calculated content of some of the BB diets in the production period are shown in Table 1. Forty data lines were randomly extracted and used to train the GMDH-type NN and the remainder $(n=27)$ to test the model. Samples of the data pattern belonging to training and testing sets used to develop NN model in BB during EEP are shown in Table 2, while the range of data lines used to develop the GMDH-type NN model for EEP in BB are summarized in Table 3.

Model development, SA and statistical procedures

In the present study, the GMDH-type $N N$ with GA method was used to develop the EEP in BB. By means of the GMDH algorithm, a model can be represented as a set of quadratic polynomials. In this way, GA are deployed to assign the number of neurons (polynomial equations) in the network and to find the optimal set of appropriate coefficients of the quadratic expressions. Detailed descriptions of GMDH-type NN with GA 
Table 2. Sample of training and testing sets (10 lines of each) used to develop the NN model for the EEP model in $B B$

\begin{tabular}{|c|c|c|c|c|c|}
\hline \multirow[b]{2}{*}{ Groups } & \multicolumn{4}{|c|}{ Input variables } & \multirow[b]{2}{*}{$\begin{array}{l}\text { Output } \\
\text { EEP } \\
\text { (egg/ } \\
\text { bird) }\end{array}$} \\
\hline & $\begin{array}{l}\text { ME } \\
\text { intake } \\
\text { (MJ/ } \\
\text { bird/ } \\
\text { day) }\end{array}$ & $\begin{array}{l}\text { CP } \\
\text { intake } \\
\text { (g/bird/ } \\
\text { day) }\end{array}$ & $\begin{array}{l}\text { Met } \\
\text { intake } \\
\text { (g/bird/ } \\
\text { day) }\end{array}$ & $\begin{array}{l}\text { Lys } \\
\text { intake } \\
\text { (g/bird/ } \\
\text { day) }\end{array}$ & \\
\hline \multirow{10}{*}{$\begin{array}{l}\text { Training } \\
\text { set }\end{array}$} & $1 \cdot 90$ & $24 \cdot 4$ & $0 \cdot 54$ & $1 \cdot 23$ & $0 \cdot 62$ \\
\hline & $1 \cdot 81$ & $21 \cdot 6$ & $0 \cdot 60$ & $1 \cdot 10$ & $0 \cdot 55$ \\
\hline & $1 \cdot 89$ & $23 \cdot 3$ & $0 \cdot 60$ & $1 \cdot 04$ & $0 \cdot 54$ \\
\hline & $1 \cdot 79$ & $21 \cdot 4$ & 0.59 & 0.93 & $0 \cdot 62$ \\
\hline & $1 \cdot 68$ & $21 \cdot 2$ & 0.53 & 0.95 & $0 \cdot 53$ \\
\hline & $2 \cdot 01$ & $24 \cdot 8$ & $0 \cdot 76$ & $1 \cdot 22$ & $0 \cdot 62$ \\
\hline & $1 \cdot 96$ & $24 \cdot 5$ & 0.62 & $1 \cdot 09$ & $0 \cdot 62$ \\
\hline & $1 \cdot 84$ & $23 \cdot 6$ & $0 \cdot 50$ & $1 \cdot 19$ & $0 \cdot 56$ \\
\hline & $1 \cdot 88$ & $23 \cdot 5$ & $0 \cdot 59$ & $1 \cdot 04$ & $0 \cdot 57$ \\
\hline & $1 \cdot 85$ & $22 \cdot 9$ & $0 \cdot 70$ & $1 \cdot 13$ & $0 \cdot 6$ \\
\hline \multirow{10}{*}{$\begin{array}{l}\text { Testing } \\
\text { set }\end{array}$} & $1 \cdot 96$ & $25 \cdot 1$ & 0.53 & $1 \cdot 26$ & $0 \cdot 61$ \\
\hline & $1 \cdot 75$ & $22 \cdot 4$ & $0 \cdot 50$ & $0 \cdot 98$ & $0 \cdot 58$ \\
\hline & $1 \cdot 79$ & $22 \cdot 1$ & 0.53 & 0.99 & $0 \cdot 51$ \\
\hline & $1 \cdot 88$ & $25 \cdot 0$ & 0.66 & $1 \cdot 32$ & $0 \cdot 61$ \\
\hline & $1 \cdot 88$ & $22 \cdot 4$ & $0 \cdot 62$ & $1 \cdot 04$ & $0 \cdot 55$ \\
\hline & $1 \cdot 86$ & $22 \cdot 2$ & $0 \cdot 61$ & $1 \cdot 03$ & 0.63 \\
\hline & $1 \cdot 85$ & $23 \cdot 8$ & $0 \cdot 51$ & $1 \cdot 11$ & 0.63 \\
\hline & $1 \cdot 85$ & $22 \cdot 9$ & $0 \cdot 55$ & $1 \cdot 02$ & $0 \cdot 61$ \\
\hline & $1 \cdot 88$ & $23 \cdot 8$ & $0 \cdot 52$ & $1 \cdot 11$ & $0 \cdot 56$ \\
\hline & $1 \cdot 85$ & $23 \cdot 4$ & 0.58 & $1 \cdot 03$ & $0 \cdot 62$ \\
\hline
\end{tabular}

method model terminology, development, application and examples of using this approach have been reported by several researchers (Atashkari et al. 2005; Nariman-Zadeh et al. 2005). The variables of interest in this model were the dietary intake levels of $M E(M J / b i r d / d a y), C P(g / b i r d / d a y)$, Met (g/bird/day), Lys (g/bird/day) and weekly egg production (eggs/bird) during early production (from 24 to 29 weeks of age). Datasets were imported into the software GEvoM for GMDH-type NN training (GEvoM 2009).To find the best structure, the GA parameter values of 600 generations, cross-over probability of 0.85 and mutation probability of 0.1 were set. However, the model produced by the GMDH-type $\mathrm{NN}$ is in the form of a complex equation and the effect of an input variable on the model is not clearly evident. Researchers are even more interested in the interpretability issue rather than the accuracy of the models, thus SA of the obtained model is carried out to evaluate the input parameters' influence on model output. SA is the study of the relationship between the input and output of a model. In this way, the proposed EEP model is subjected to SA. Most of the SA met in the literature is based on derivatives. Indeed the derivative $\left(\partial y_{i} / \partial x_{i}\right)$ of an output $\left(y_{j}\right.$, e.g. EEP) $v$. an input ( $x_{i}$, e.g. ME, CP, Met and Lys) can be inferred as a mathematical definition of the sensitivity of model output $v$. input variables (Zurada et al. 1994; Saltelli et al. 2008). In fact in this method, model output is derived with respect to each input variable. These derivations are represented as polynomial equations that are plotted in a special range for each investigated input variable while the other input variables postulated as a constant value. The plotted curve can be used to compare the sensitivity of model with variables, determining the most influential input and selecting the optimum value to optimize the output. In other words, maximum sensitivity of each input variable is considered as optimum value for maximizing the EEP model. The SA procedures were conducted using MATLAB software (Matlab Company 2008). The accuracy of the model was determined using coefficient of determination $\left(R^{2}\right)$, mean square error (MSE), root mean square error (RMSE), mean absolute deviation (MAD) and bias.

\section{RESULTS}

The optimal structure of the evolved two-hidden layer GMDH-type NN was produced from the GA for modelling the EEP found with only two hidden neurons. This structure of the developed NN model reflects the design of the GA. The polynomial Eqns (1) (3) show the quantitative relationships between input and output variables. These polynomial equations were obtained as

$$
\begin{aligned}
y_{1}= & -1.455+1.62 \mathrm{ME}+1.4 \mathrm{Met}^{2}-0.073 \mathrm{ME}^{2} \\
& +2.135 \mathrm{Met}^{2}-2.08 \mathrm{ME} \times \text { Met } \\
y_{2}= & -1.91+0.23 \mathrm{CP}-0.566 \mathrm{Lys}-0.004 \mathrm{CP}^{2} \\
& +0.238 \mathrm{Lys}^{2}-0.002 \mathrm{CP} \times \text { Lys } \\
\mathrm{EEP}= & 3.23-4.3 y_{1}-6.3 y_{2}+21.85 y_{1}^{2} \\
& +23.966 y_{2}^{2}-35.46 y_{1} \times y_{2}
\end{aligned}
$$

The ability of GMDH-type NN to predict EEP in BB is demonstrated in Fig. 1. Results of the developed GMHD-type NN models revealed close agreement between observed and predicted values of EEP. The statistical results for the training and testing set of the GMDH-type NN model are summarized in Table 4. Polynomial equations obtained by the GMDH model were subjected to SA. Corresponding EEP sensitivity 
Table 3. Ranges of data $(n=67)$ used to develop the group method of data handling-type neural network model for EEP in $B B$

\begin{tabular}{|c|c|c|c|c|c|}
\hline \multirow[b]{2}{*}{ Range } & \multicolumn{4}{|c|}{ Input variables* } & \multirow{2}{*}{$\begin{array}{l}\text { Output } \\
\text { variablet EEP } \\
\text { (eggs/bird) }\end{array}$} \\
\hline & ME (MJ/bird/day) & CP (g/bird/day) & Met (g/bird/day) & Lys (g/bird/day) & \\
\hline Min-Max & $1 \cdot 63-2 \cdot 01$ & $20 \cdot 4-26 \cdot 7$ & $0 \cdot 48-0 \cdot 76$ & $0 \cdot 91-1 \cdot 4$ & $0 \cdot 5-0 \cdot 65$ \\
\hline Mean \pm S.D. & $1 \cdot 8 \pm 0 \cdot 09$ & $23 \cdot 3 \pm 1 \cdot 5$ & $0.57 \pm 0.067$ & $1 \cdot 1 \pm 0 \cdot 11$ & $0 \cdot 58 \pm 0 \cdot 040$ \\
\hline
\end{tabular}

* ME, metabolizable energy (MJ/bird/day); CP, crude protein (g/bird/day); Met, methionine (g/bird/day); Lys, lysine (g/bird/day).

+ EEP, eggs/bird; the egg production is average production for 24-29 weeks of age.

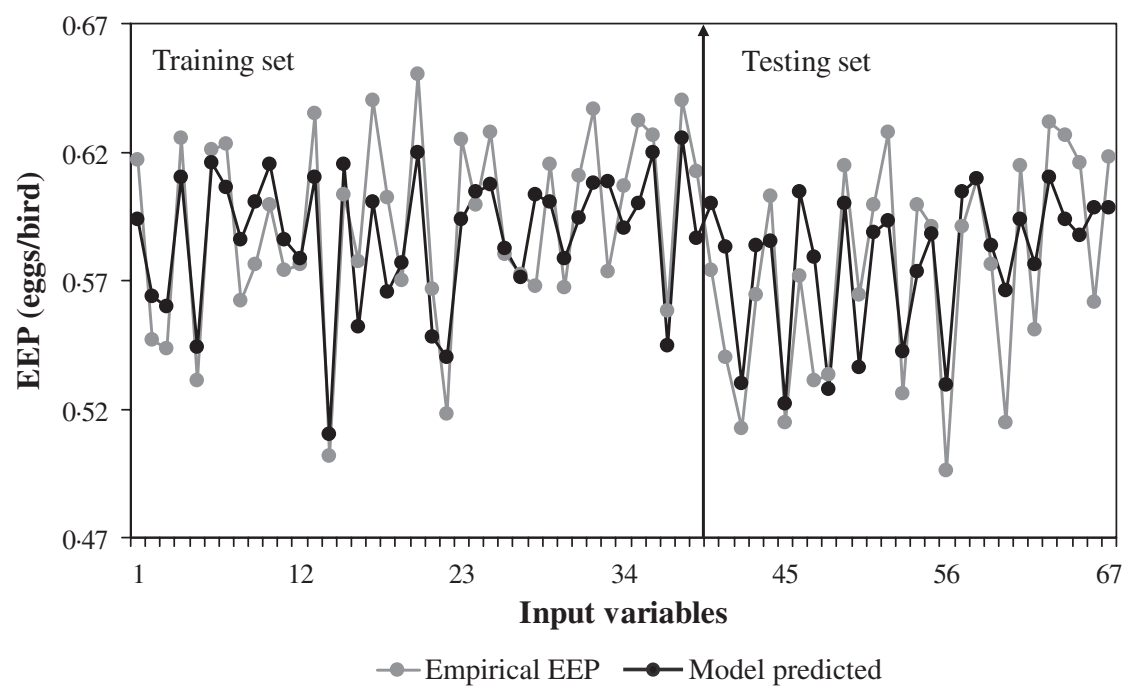

Fig. 1. NN model-predicted EEP in comparison with actual data in BB for the training and testing sets.

statements obtained for each input variable were as follows in Eqns (4-7):

$$
\begin{aligned}
\frac{\partial F}{\partial x_{1}}= & \frac{\partial F}{\partial y_{1}} \times \frac{\partial y_{1}}{\partial x_{1}} \\
= & \left(-4.3+43.7 y_{1}-35 \cdot 46 y_{2}\right)(1.62 \\
& \left.+0.146 x_{1}-2.08 x_{3}\right) \\
\frac{\partial F}{\partial x_{2}}= & \frac{\partial F}{\partial y_{2}} \times \frac{\partial y_{2}}{\partial x_{2}} \\
= & \left(-6 \cdot 3+47.92 y_{2}-35.46 y_{1}\right)(0.23 \\
& \left.+0.008 x_{2}-0.004 x_{4}\right) \\
\frac{\partial F}{\partial x_{3}=} & \frac{\partial F}{\partial y_{1}} \times \frac{\partial y_{1}}{\partial x_{3}} \\
= & \left(-4.3+43.7 y_{1}-35.46 y_{2}\right)\left(1.4+2.27 x_{3}\right. \\
& \left.-2.08 x_{1}\right) \\
\frac{\partial F}{\partial x_{4}}= & \frac{\partial F}{\partial y_{2}} \times \frac{\partial y_{2}}{\partial x_{4}} \\
= & \left(-6.3+47.92 y_{2}-35.46 y_{1}\right)(0.56 \\
& \left.+0.476 x_{4}-0.002 x_{2}\right)
\end{aligned}
$$

where $F, x_{1}, x_{2}, x_{3}$ and $x_{4}$ stand for EEP, ME, CP, Met and Lys, respectively. The SA results obtained for the EEP model for investigated dietary nutrients are shown in Figs $2-5$. The variation in each variable in the plotted curve is kept within the data range, i.e. the considered variation of each input variable is in the range described in Table 3.

\section{DISCUSSION}

Results showed that the evolved GMDH-type NNs have been successful in obtaining a model for the prediction of EEP in BB. All input variables were accepted by the model, i.e. the GMDH-type NN provides an automated selection of essential input variables and builds polynomial equations to model EEP. This is in agreement with previous studies aimed at investigating the effect of dietary nutrients on $\mathrm{BB}$ performance (Bornstein \& Lev 1982; Cave 1984; Hudson et al. 2000). Overall calculated values of accuracy indices revealed that the training set 
Table 4. Model statistics and information for EEP in $B B^{*}$

\begin{tabular}{llc}
\hline \hline & \multicolumn{2}{c}{ Datasets } \\
\cline { 2 - 3 } Statistics & Neural training & Neural testing \\
\hline$R^{2}$ & 0.997 & 0.996 \\
MSE & 0.001 & 0.0012 \\
RMSE & 0.0316 & 0.0346 \\
Bias & 0.003 & -0.008 \\
Hidden layer & & 2 \\
Hidden neurons & & 2 \\
\hline \hline
\end{tabular}

* MSE, mean square error; RMSE. root MSE.

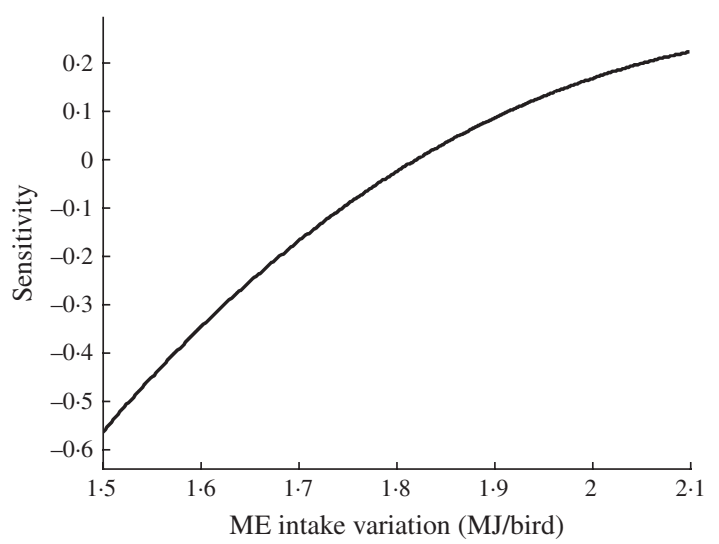

Fig. 2. Sensitivity of EEP in BB with respect to $M E$ intake variation.

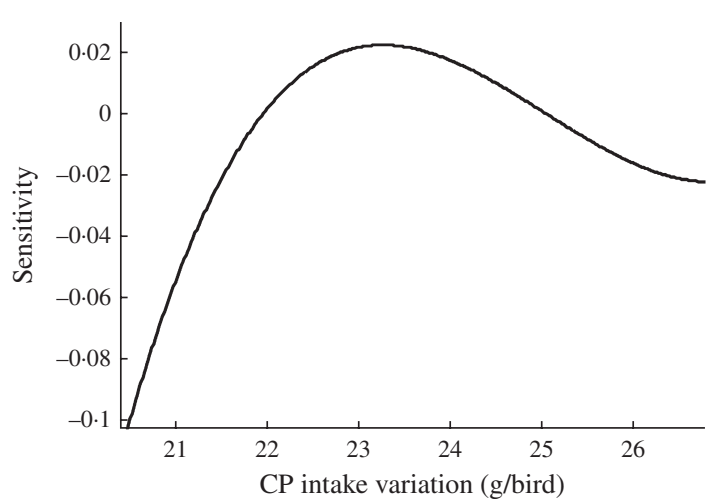

Fig. 3. Sensitivity of EEP in BB with respect to $C P$ intake variation.

provided a better prediction of EEP compared with that for testing (Table 4). This is in good agreement with Ahmadi et al. (2008) who reported the same findings in the prediction of true ME content of feather meal using GMDH-type NN. As the NN models are developed based on the training sets, achieving higher values of

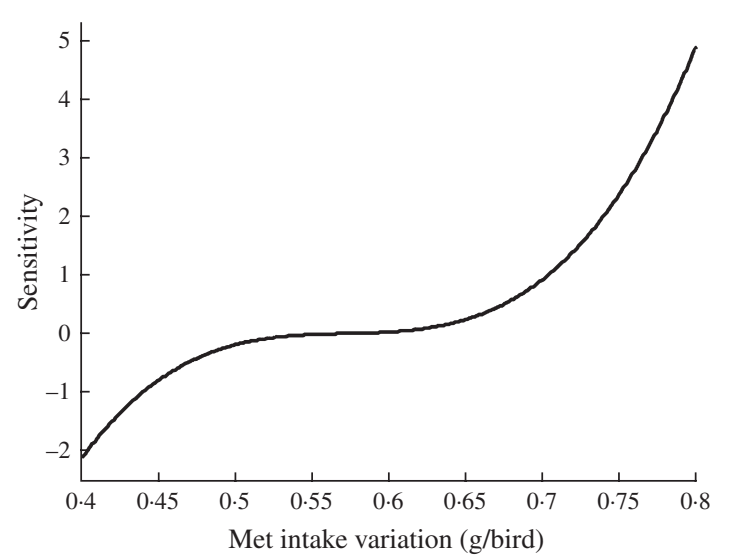

Fig. 4. Sensitivity of EEP in BB with respect to Met intake variation.

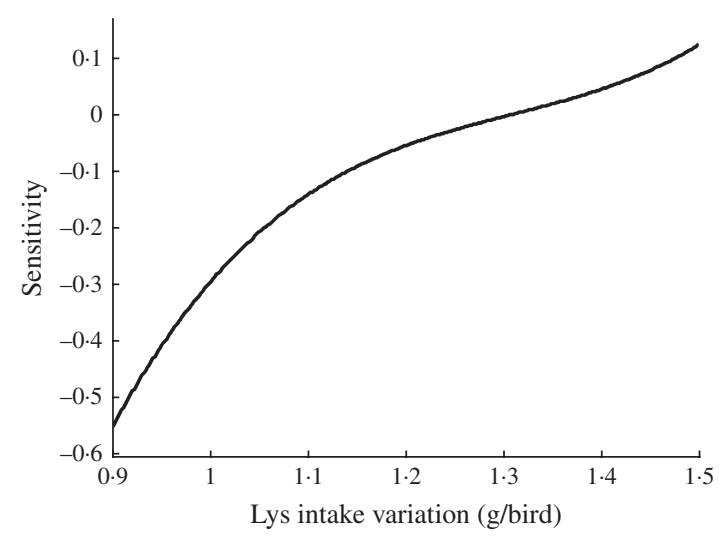

Fig. 5. Sensitivity of EEP in BB with respect to Lys intake variation.

accuracy in these groups are to be expected. Overall calculated values of bias showed higher values for the training set compared with that for testing. This is in agreement with Mottaghitalab et al. (2010), who investigated the ability of GMDH-type NN to predict caloric and feed efficiency in turkeys. Figures 2-5 show the SA results. As these figures demonstrate, the EEP model is considerably influenced by Met and Lys, the first and second limiting amino acid. However, EEP model sensitivity decreased with $\mathrm{ME}$ and $\mathrm{CP}$ variation, respectively. As Fig. 2 shows, ME intake of 1.9-2.1 MJ/ bird/day provides the most increasing effect on model output. Results from SA of the EEP model for CP variation illustrate that maximum increasing effect of $\mathrm{CP}$ would be achieved at $23 \mathrm{~g} /$ day/bird (Fig. 3). These results are in agreement with Waldroup et al. (1976), who suggested $20-22 \mathrm{~g}$ protein/bird/day and $1.8 \mathrm{MJ}$ ME/bird/day for BB fed with corn-soybean meal diets (Waldroup et al. 1976). By the same token, Ross 
Breeder company's recommendations for ME and CP intake during early stages of egg production were $1.76 \mathrm{MJ} /$ bird/day and $22.5 \mathrm{~g} / \mathrm{bird} /$ day, respectively (Ross Breeders Ltd 2005). The protein variation provided least sensitivity in the proposed model. Low sensitivity of production in BB to protein variation may be a proof for the concept of studies designed to decrease protein in breeder diets and balance essential amino acids in order to decrease dietary costs and excretion of nitrogen to the environment (Lopez \& Leeson 1994, 1995). The protein content of a BB feed can be lowered with supplemental Met and Lys. Moreover, the energy content of the diet will usually increase when protein is lowered and amino acids added. Therefore, a smaller amount of feed will be needed to meet the hen's energy requirement. In other words, use of supplemental Met and Lys will reduce daily protein intake and reduce nitrogen excretion (Harms \& Russell 1998). There is limited published information on special BB amino acid requirements, especially for Met and Lys (Harms 1992). The SA of the EEP model to Met intake variation indicated that maximum increasing effect of this nutrient would be achieved at $0 \cdot 65-0 \cdot 8 \mathrm{~g} / \mathrm{bird} /$ day (Fig. 4). This range could be considered as the optimum level of this nutrient. The range is higher than that suggested by Fisher (1998) who reported the best performance of BB at $0.47 \mathrm{~g} \mathrm{Met/bird/day.} \mathrm{However,} \mathrm{the} \mathrm{Ross} \mathrm{Breeder}$ company's recommendation for this period of production is $0.45 \mathrm{~g} / \mathrm{bird} /$ day (Ross Breeders Ltd 2005). Based on Fig. 5, increasing effect of Lys intake is in the range of $1 \cdot 3-1.5 \mathrm{~g} / \mathrm{bird} /$ day. This is in agreement with previous studies which reported that the National Research Council (NRC 1984) recommended level of Lys intake $(765 \mathrm{mg} /$ bird/day) is not adequate and higher levels of Lys are needed to support good performance by BB (Spratt \& Leeson 1987; Harms 1992; Fisher 1998). The higher values of nutrients suggested are probably because of genetic selection programmes which lead to increase in productivity and performance of $\mathrm{BB}$, and subsequently higher nutrient requirements. The Ross female parent stock recommendation for Lys during 24-29 weeks of age was $0.975 \mathrm{~g} / \mathrm{bird} /$ day (Ross Breeders Ltd 2005). The results indicated that nutrient recommendation for maximum performance in $\mathrm{BB}$, provided by the SA results, is higher than those suggested by the Ross Breeders Ltd. Such differences in nutrient requirement levels may be due to differences in genetics, environments, dietary factors and the statistical method applied. However, it would be useful to evaluate the effect of the suggested values provided in the current study for the whole production cycle. It should be noted, however, as with other data-based models, the applicability of GMDH-type NN is very dependent on the data ranges used to develop the model. Obviously, additional research with a larger experimental dataset (data that produce larger ranges) will lead to a more appropriate and applicable model.

The present study showed that the GMDH-type NN can be used to predict EEP in BB based on dietary nutrient intake. The advantage of using GMDH-type $\mathrm{NN}$ is subjecting obtained polynomial equations to analysis of the sensitivity of output with respect to input variables. SA has several effects such as obtaining the first-order approximation solution, evaluating the parameters' sensitivity, selecting proper variables and applying the results to give practical solutions.

\section{REFERENCES}

Ahmadi, H., Golian, A., Mottaghitalab, M. \& NarimanZADEH, N. (2008). Prediction model for true metabolizable energy of feather meal and poultry offal meal using group method of data handling-type neural networks. Poultry Science 87, 1909-1912.

Atashkari, K., Nariman-Zadeh, N., Pilechi, A., Jamali, A. \& YAO, X. (2005). Thermodynamic Pareto optimization of turbojet engines using multi-objective genetic algorithms. International Journal of Thermal Sciences 44, 1061-1071.

BAsheER, I. A. \& HajMeER, M. (2000). Artificial neural networks: fundamentals, computing, design, and application. Journal of Microbiological Methods 43, 3-31.

BORNSTEIN, S. \& LEV, Y. (1982). The energy requirements of broiler breeders during the pullet-layer transition period. Poultry Science 61, 755-765.

Castillo, E., Minguez, R. \& Castillo, C. (2008). Sensitivity analysis in optimization and reliability problems. Reliability Engineering and System Safety 93, 1788-1800.

CAVE, N. A. G. (1984). Effect of a high-protein diet fed prior to the onset of lay on performance of broiler breeder pullets. Poultry Science 63, 1823-1827.

Cheng, B. \& TitTerington, D. M. (1994). Neural networks: a review from a statistical perspective. Statistical Science $\mathbf{9}$, 2-54.

Faridi, A., Mottaghitalab, M., Darmani-Kuhl, H., France, J. \& Ahmadi, H. (2011). Predicting carcass energy content and composition in broilers using the group method of data handling-type neural networks. Journal of Agricultural Science Cambridge 149, 249-254.

Farrow, S. J. (1984). The GMDH algorithm. In Self-organizing Methods in Modeling: GMDH Type Algorithms (Ed. S. J. Farrow), pp. 1-24. New York: Marcel Dekker.

FISHER, C. (1998). Lysine: amino acid requirements of broiler breeders. Poultry Science 77, 124-133.

GEvoM. (2009). GMDH-type neural network designed by an evolutionary method of modelling. Rasht, Guilan, 
Iran: The University of Guilan. Available online at http:// research.guilan.ac.ir/gevom/ (verified 19 April 2011).

HARMS, R.H. (1992). A determination of the order of limitation of amino acids in a broiler breeder diet. Journal of Applied Poultry Research 1, 410-414.

Harms, R. H. \& IVEY, F. J. (1992). An evaluation of the protein and lysine requirement for broiler breeder hens. Journal of Applied Poultry Research 1, 308-314.

HaRms, R. H. \& RusselL, G. B. (1998). Adding methionine and lysine to broiler breeder diets to lower feed costs. Journal of Applied Poultry Research 7, 202-218.

HudsON, B. P., Lien, R. J. \& Hess, J. B. (2000). Effects of early protein intake on development and subsequent egg production of broiler breeder hens. Journal of Applied Poultry Research 9, 324-333.

Kucuk, I. \& DerebasI, N. (2006). Sensitivity analysis for estimation of power losses in magnetic cores using neural network. Journal of Physics and Chemistry of Solids 67, 2473-2477.

Latour, M. A., Peebles, E. D., Boyle, C. R., Doyle, S. M., PANSKY, T. \& BRAKE, J. D. (1996). Effects of breeder hen age and dietary fat on embryonic and neonatal broiler serum lipids and glucose. Poultry Science 75, 695-701.

LeE, C. J. \& HsiunG, T. K. (2009). Sensitivity analysis on a multilayer perceptron model for recognizing liquefaction cases. Computers and Geotechnics 36, 1157-1163.

LOPEZ, G. \& LeESON, S. (1994). Egg weight and offspring performance of older broiler breeders fed low-protein diets. Journal of Applied Poultry Research 3, 164-170.

LOPEZ, G. \& LeESON, S. (1995). Response of broiler breeders to low-protein diets. 1. Adult breeder performance. Poultry Science 74, 685-695.

Matlab Company. (2008). Matlab User Guide: Version 7.0. Natick, MA: MathWorks Inc.

Mottaghitalab, M., Faridi, A., Darmani-Kuhi, H., France, J. \& Ahmadi, H. (2010). Predicting caloric and feed efficiency in turkeys using the group method of data handling-type neural networks. Poultry Science 89, 1325-1331.

Nariman-Zadeh, N., Atashkari, K., Jamali, A. \& Pilechi, A. \& $\mathrm{YAO}_{\mathrm{AO}}$ X. (2005). Inverse modeling of multiobjective thermodynamically optimized turbojet engines using GMDH-type neural networks and evolutionary algorithms. Engineering Optimization 37, 437-462.
Nariman-Zadeh, N., Darvizeh, A. \& Ahmad-Zadeh, G. R. (2003). Hybrid genetic design of GMDH-Type neural networks using singular value decomposition for modeling and prediction of the explosive cutting process. Proceedings of the Institution of Mechanical Engineers B: Journal of Engineering Manufacture 217, 779-790.

National Research Council (1984). Nutrient Requirements of Poultry. 8th Revised edition. Washington, DC: National Academy Press.

Peebles, E. D., Zumwalt, C. D., Doyle, S. M., Gerard, P. D., Latour, M. A., Doyle, C. R. \& Smith, T. W. (2000a). Effects of dietary fat type and level on broiler breeder performance. Poultry Science 79, 629-639.

Peebles, E. D., Zumwalt, C. D., Doyle, S. M., Gerard, P. D., Latour, M. A., Doyle, C. R. \& SMith, T. W. (2000b). Effects of breeder age and dietary fat source and level on broiler hatching egg characteristics. Poultry Science 79, 698-704.

Ross Breeders Ltd. (2005). Parent Stock Management Manual for Ross 308. Newbridge, UK: Ross Breeders Ltd.

Saltelli, A., Ratto, M., Andres, T., Campolongo, F., Cariboni, J., Gatelli, D., Salsana, M. \& Tarantola, S. (2008). Global Sensitivity Analysis. The Primer. New York: John Wiley \& Sons, Ltd.

SeYedAn, B. \& ChInG, C. Y. (2006). Sensitivity analysis of freestream turbulence parameters on stagnation region heat transfer using a neural network. International Journal of Heat and Fluid Flow 27, 1061-1068.

SPRATT, R. S. \& LeESON, S. (1987). Broiler breeder performance in response to diet protein and energy. Poultry Science 66, 683-693.

Waldroup, P.W., Hazen, K.R., Russell, W.D. \& JoHnson, Z. B. (1976). Studies on the daily protein and amino acid needs of broiler breeder hens. Poultry Science 55, 2342-2347.

WILSON, H. R. \& HARMS, R. H. (1986). Performance of broiler breeders as affected by bodyweight during the breeding season. Poultry Science 65, 1052-1057.

Zurada, J. M., Malinowski, A. \& Cloete, I. (1994). Sensitivity analysis for minimization of input data dimension for feed forward neural network. In: Proceedings of the IEEE International Symposium on Circuits and Systems, London, 28 May-2 June 1994, vol. 6, pp. 447-450. London: IEEE Press. 